\title{
Patterns of torture among forcibly displaced Eritrean men in California: A cross-sectional study
}

\author{
Nicholas Nelson'1, P. Suzanne Portnoy', Jenna O. Kupa', Isabelle Rocroi ${ }^{1}$, Emily \\ Tatel $^{1}$, Alejandro Diaz ${ }^{1}$ and Kala M. Mehta ${ }^{1,2}$
}

\section{Key points of interest}

- History of torture is common among male Eritrean asylum seekers; the most common forms are beating and forced positioning, and the most common sequelae include musculoskeletal problems and post-traumatic stress disorder.

\begin{abstract}
Introduction: This study was conducted to address a lack of information in the literature regarding the frequency and consequences of specific types of torture and abuse among Eritreans seeking asylum in the United States.

Methods: Cross-sectional study of Eritreans seeking asylum in the United States presenting to a human rights clinic for forensic medical and psychological evaluations based on Istanbul Protocol. Reports were eligible for inclusion if subjects: 1) immigrated from Eritrea 2) reported torture and abuse in Eritrea, 3) were 18 or older. 59 reports met inclusion criteria. Demographic features of individuals, reported

1) Human Rights Clinic, Highland Hospital

2) University of California, San Francisco. Correspondence to:

paportnoy@alamedahealthsystem.org
\end{abstract}

history and specific types of torture, and physical and psychological sequelae were analyzed.

Results: Over 300 instances of torture were reported, an average of about 6 per person. The primary forms of torture reported were beating $(87.7 \%)$ and forced positioning (57.9\%). $90 \%$ of asylum seekers examined had physical findings which were consistent with the torture they reported, some of which had clinical as well as forensic significance. $86 \%$ of asylum seekers met diagnostic criteria for post-traumatic stress disorder.

Conclusion: Eritreans seeking asylum in the United States bear a high burden of post-traumatic physical and psychological morbidity.

Keywords: Asylum seekers, Tortures, Scars, Physical assessment, Eritrea

\section{Introduction}

The last decade has seen an inexorable rise in the global population of forcibly displaced people (Ignatieff, Keeley, Ribble, \& McCammon, 2016; UNHCR, 2018). According to the United Nations High Commissioner for Refugees, the global refugee population is now at the highest level ever recorded and has approximately doubled since 2012 (UNHCR, 2018). Over the last two years, increasingly draconian political responses to forcibly displaced people (including travel bans, separation of children from their parents, and 
detention under inhumane conditions) have thrust dynamics of involuntary migration to the forefront of public consciousness.

Forcibly displaced people are likely to have witnessed and experienced deprivation, abuse, violence, and have suffered physical and psychological consequences. In a seminal study of adult outpatients in a Los Angeles primary care clinic, $6.6 \%$ were found to have experienced torture as defined by the United Nations (Eisenman, Keller, \& Kim, 2000). A similar study of foreign-born but otherwise unselected outpatients conducted in New York found that $11 \%$ had also experienced torture (Crosby et al., 2006). These two studies, while hardly a comprehensive body of literature, nevertheless suggest the alarming possibility that, among immigrants in diverse urban communities in the United States, the prevalence of having been tortured may be comparable to that of low back pain or type 2 diabetes (Bullard et al., 2016; Freburger et al., 2009). While studies of unselected patients make this point dramatically, the prevalence of torture is much higher among forcibly displaced people. A recent systematic review found that the prevalence of torture (variably defined) among asylum seekers across 23 studies conducted in 10 high-income countries was $30 \%$ (Kalt, Hossain, Kiss, \& Zimmerman 2013).

Primary care clinicians are typically illequipped by their training to recognize, evaluate, and treat forcibly displaced people who have survived torture and other traumatic experiences. Nonetheless, we find ourselves living in an unprecedented and global epidemic of enforced migration. As in any other epidemic, clinicians must understand the origins of the suffering they aim to alleviate, regardless of whether its sources are biological, psychosocial, or political (Virchow, 1985). Broad educational initiatives can help to address this and are indispensable to training the next genera- tion of primary care clinicians (Metalios et al., 2008). Detailed studies of specific diaspora communities are equally important to practicing clinicians who work with members of these communities, because they improve clinicians' understanding of common experiences in specific groups. Clinicians' knowledge of displaced people must evolve with waves of migration; in an ever more connected and mobile world, local primary care must be responsive to global events. Moreover, clinicians have a clear, internationally recognized obligation to detect, describe, and decry human rights violations wherever they encounter them.

Despite its small population, Eritrea is currently one of the ten countries which produce the largest number of displaced people in the world (UNHCR, 2018).In 2017, the US Census Bureau estimated that over 38,000 people born in Eritrea live in the United States, although precise numbers are uncertain since prior to 2000, classified Eritreans as Ethiopians (U.S. Census Bureau, 2017). The largest proportion of Eritreans living in America are in California, primarily in Los Angeles and in the San Francisco Bay Area. Previous studies have described Eritrean immigrants' experiences with healthcare systems in destination countries (Walliman \& Balthasar, 2019; Jonzon, Lindkvist, \& Johansson, 2015) and examined post-traumatic mental health conditions (Getnet, Medhin, \& Alem, 2019; Melamed, Chernet, Labhart, ProbstHensch, and Pfeiffer, 2019) and their implications for health care utilization (Siman-Tov, Bodas, Wang, Alkan, \& Adini, 2019). Searches of PubMed and Google Scholar (1975-2021) did not reveal any papers describing the epidemiology of torture among Eritrean asylum seekers in the United States, and this crosssectional study was conducted to help resolve this gap in the literature. 
Eritrea has experienced two large waves of outward migration in the last seventy years. The first began during the protracted and bloody war for independence from Ethiopia, which spanned from 1961 to 1991 and was accompanied by a civil war within Eritrea between rival nationalist factions. After independence there was a lull in emigration before the beginning of the present wave, which began when the ruling People's Front for Democracy and Justice party began an extensive program of militarization and repression in the wake of the 1998-2000 border war with Ethiopia (Hepner, 2009). Eritrea instituted a national service requirement for all citizens in 1995, excepting only veterans of the war for independence and the disabled, which prescribes an 18 month commitment with six months dedicated to military training followed by twelve months in military service or in work on civil infrastructure and agricultural projects under military discipline. Prior to the 1998-2000 border war, conscripts were discharged after completing this 18 month period of service. Since the war, however, national service has become open-ended for most conscripts. The universal liability to indefinite, barely paid service disrupts social and economic networks and curtails individuals' ability to pursue educational and economic advancement, and to provide for their families (Hirt \& Mohammad, 2013). Harsh punishments, arbitrary detention under inhumane conditions, and torture are commonly employed by agents of the Eritrean state within and without the national service (United Nations, Human Rights Council, 2016). Those who attempt to avoid or desert from national service are subject to a shoot-to-kill policy if they flee across Eritrea's borders, and when apprehended are commonly detained for periods ranging from months to years and tortured (Kibreab, 2009). The indefinite nature of national service, its disruption of individual lives and family networks, its interference of the possibility of individual advancement and the ability to cultivate and provide for a family, and the prevalence of harsh conditions, arbitrary detention, and torture within national service have combined to make it the primary driver of the contemporary exodus of young Eritreans (Kibreab, 2014).

This study was conducted at a Human Rights Clinic (HRC) based in Northern California, which has served asylum seekers since 2003. HRC provides longitudinal primary care and forensic medical and psychological evaluations for use in asylum proceedings. These evaluations document physical and psychological stigmata of torture and other forms of abuse in order to assist immigration officials and judges who are responsible for granting or denying asylum. Forensic evaluations make a substantial difference in the likelihood of an asylum claim being granted, and can be performed by any trained primary care or mental health clinician (McKenzie, Bauer, \& Reynolds, 2019).

\section{Methods}

\section{Study Design}

This is a cross-sectional survey of forensic medical reports prepared on behalf of Eritrean asylum seekers using retrospective qualitative and quantitative methods. Archived reports were anonymized before analysis to protect patient confidentiality, and treatment plans were not altered based on participation in the study. All procedures were approved by the Institutional Review Board at Highland Hospital.

\section{Setting}

All reports were drawn from HRC archives. Reports completed between 2012 and 2018 were reviewed. No patients were contacted as part of the data collection or analysis. 


\section{Participants}

At the time of the study 438 evaluation reports were available for review, documenting various physical and psychological residua of torture in asylum seekers from a wide range of countries, predominately Guatemala, Honduras, El Salvador, and Eritrea. Reports were eligible for inclusion if the subjects: 1) immigrated from Eritrea 2) reported torture and abuse in Eritrea, 3) were 18 or older, and 4) were not evaluated solely for female genital cutting (FGC). 59 reports met inclusion criteria. Reports documenting FGC were excluded because at HRC patients with FGC typically do not undergo further extensive evaluation for forensic purposes $(n=89)$. Anatomic evidence of FGC is legally recognized as sufficient grounds for asylum in the United States, and since the purpose of forensic evaluations is to provide information likely to bear on asylum decisions, a comprehensive trauma history and physical exam are typically not recorded for individuals who are evaluated for confirmation of FGC. Aside from forensic evaluations, clinical documentation of posttraumatic sequelae in patients evaluated for FGC was not always available, and in any case incommensurate with the detailed information obtained from individuals seeking asylum on grounds other than FGC. Finally, although technically illegal, FGC has been highly prevalent and continues to be practiced in many parts of Eritrea, and while it is viewed in many countries as a human rights violation equivalent to torture for the purposes of immigration policy, it is not so regarded by many who practice, sanction, and/or have experienced it in Eritrea (Zerai, 2003). There were no reports in which evaluators deemed that asylum claimants did not manifest findings that were consistent with some or all of their alleged history of trauma or found positive evidence of mendacity or malingering.

\section{Data Collection}

Coding frameworks were developed by the research team to identify and catalogue variables of interest in the narrative of the medical reports reviewed. The frameworks drew from the World Health Organization's 2002 World Report on Violence and Health, (Krug et al., 2002) and defined torture in accordance with the United Nations' Convention Against Torture (United Nations, General Assembly, 1984). Two research assistants, working separately, abstracted qualitative data from the narrative reports. Deductive content analysis was used to categorize demographic characteristics, number and place of detentions, types of abuse and torture described. Inter-rater reliability of the research assistants was $95 \%$. Records reviewed by research assistants were anonymized by clinicians prior to review, and abstracted data were compiled under identifying numbers in a secure spreadsheet prior to analysis.

\section{Statistical Analyses}

We examined demographics, features of detention, types of reported torture, geographical location of torture within Eritrea, and consistency of observed physical and/or psychological sequelae of torture (UNHCR, 1999).

\section{Results}

Of the 59 subjects, $91.5 \%$ were male with a mean age of 37 years $(S D=8.4)$. Nearly half were natives of the capital city of Asmara. $72.5 \%$ had completed a high school or higher education. About a third of subjects described themselves as business people (15.3\%) or students/teachers $(20.4 \%)$, although many other occupations were represented and some data were missing (11.9\%). The overwhelming majority were monolingual Tigrinya speakers.

Asylum seekers reported between one and six separate instances of detention each, with 
$78.8 \%$ reporting three or fewer. Over 300 instances of torture were reported, with an average of six instances per person. Most individuals reported torture occurring while in a detention facility $(82 \%)$. The most commonly reported sites of detention and torture were Sawa $(20 \%)$, which is the central training site of national service conscripts and armed forces recruits, and Adi Abeto (19\%), which is the primary detention facility for the capital Asmara and its vicinity. Other common sites included Wi'a (12\%) and Assab (10\%), both port cities on the Red Sea, and various jails and police stations within Asmara itself $(10 \%)$. These findings correspond substantially to previous descriptions of the network of detention and torture centers in Eritrea by Amnesty International (Amnesty International, 2013), and the Office of the High Commissioner for Human Rights (United Nations, Human Rights Council, 2015; United Nations, Human Rights Council, 2016).

Asylum seekers reported inhumane conditions of detention; prevalence figures for common themes are given in Table 1 . Most reported having been kept in overcrowded prisons without sufficient room for all detainees to lie down to sleep, which were generally described as windowless, unventilated, without artificial light, and constructed of concrete and sheet metal or made from re-purposed shipping containers. Detainees reported being confined to such spaces with only an open container as a toilet, inadequately fed, and let out only to defecate daily or participate in hard labor. Reports of epidemic diarrheal illness, skin infections, and arthropod infestations (e.g. lice and scabies) were common. Reports of exposure to extremes of temperature were also common, as would be expected in uninsulated and poorly ventilated buildings in the region; night time low temperatures in Asmara average $<10^{\circ} \mathrm{C}$ between September and March, whereas daytime highs average in Assab, on the southeastern coast, average $>$ $35^{\circ} \mathrm{C}$ between April and October.

Table 1. Conditions of detention reported by Eritrean asylum seekers

\begin{tabular}{lcc}
\hline $\begin{array}{l}\text { Reported Conditions of De- } \\
\text { tention (n=57) }\end{array}$ & $\mathbf{n}$ & $\mathbf{\%}$ \\
\hline $\begin{array}{l}\text { Inadequate sanitary facilities } \\
\text { Inadequate nutrition in deten- }\end{array}$ & 44 & 74 \\
tion & 74 \\
Exposure to extreme tempera- & 42 & 71 \\
tures in detention & & \\
Lack of access to medical care & 40 & 68 \\
Overcrowding & 31 & 53 \\
Light deprivation & 29 & 49 \\
Prolonged sun exposure & 22 & 37 \\
Pests/arthropod infestations & 20 & 33 \\
Solitary confinement & 11 & 18
\end{tabular}

Many forms of torture were reported, the most common being beating (with or without weapons) and forced positioning (Table 2). Falanga, (beating the soles of the feet) was a common sub-type of beating. Forced labor, rape, sexual humiliation, burning, electrocution, gunshot wounds, and simulated drowning were also reported. The most common form of forced positioning is known in Eritrea as "Otto," (after the Italian word for the number 8, which the bound victim supposedly resembles,) and consists of binding the elbows or wrists together behind the back, binding the ankles together, and then binding the ankles to the arms with an intervening rope. (Figure 1, United Nations, Human Rights Council, 2015).

A variant in which the victim is suspended by the intervening rope (Figure 2) is known as "Helicopter". 
Table 2. Types of abuse reported by Eritrean asylum seekers

\begin{tabular}{lll}
\hline Reported Type of Abuse & n & \% \\
\hline $\begin{array}{l}\text { Beating (with or without a } \\
\text { weapon) }\end{array}$ & 52 & 87.7 \\
$\begin{array}{l}\text { Binding and Forced Posi- } \\
\text { tioning }\end{array}$ & 34 & 57.9 \\
$\begin{array}{l}\text { Forced Labor } \\
\text { Falanga }\end{array}$ & 23 & 39 \\
$\begin{array}{l}\text { Substances applied to skin to } \\
\text { attract insects }\end{array}$ & 5 & 8.8 \\
Rape/Sexual Assault & 3 & 5.3
\end{tabular}

Asylum seekers indicated that torturers favored means which leave few permanent marks, such as beating with hoses or batons, and that they used the environment to their advantage. For example, torturers would withhold shoes to discourage escape over rough terrain, force prisoners to lie or roll on sharp rocks or gravel, expose prisoners to extremes of temperature, and apply substances such as milk or honey intended to attract insects to the skin of restrained victims.

Physical findings ranged from nonspecific abrasion and laceration scars to more specific lesions such as ligature scars, ligamentous injuries, compressive neuropathies, clinical and radiographic evidence of untreated fractures which healed with malunion, and neurocognitive impairment due to traumatic brain injury. Ligamentous laxity and peripheral nerve lesions were more common among patients who had been subjected to "Otto" and "Helicopter", because both forms of forced positioning involve circumferential compression of the extremities and (especially in the case of $\mathrm{He}$ licopter) abnormal stress on the muscles and ligaments of the pelvic and shoulder girdles, particularly the shoulders since these are not

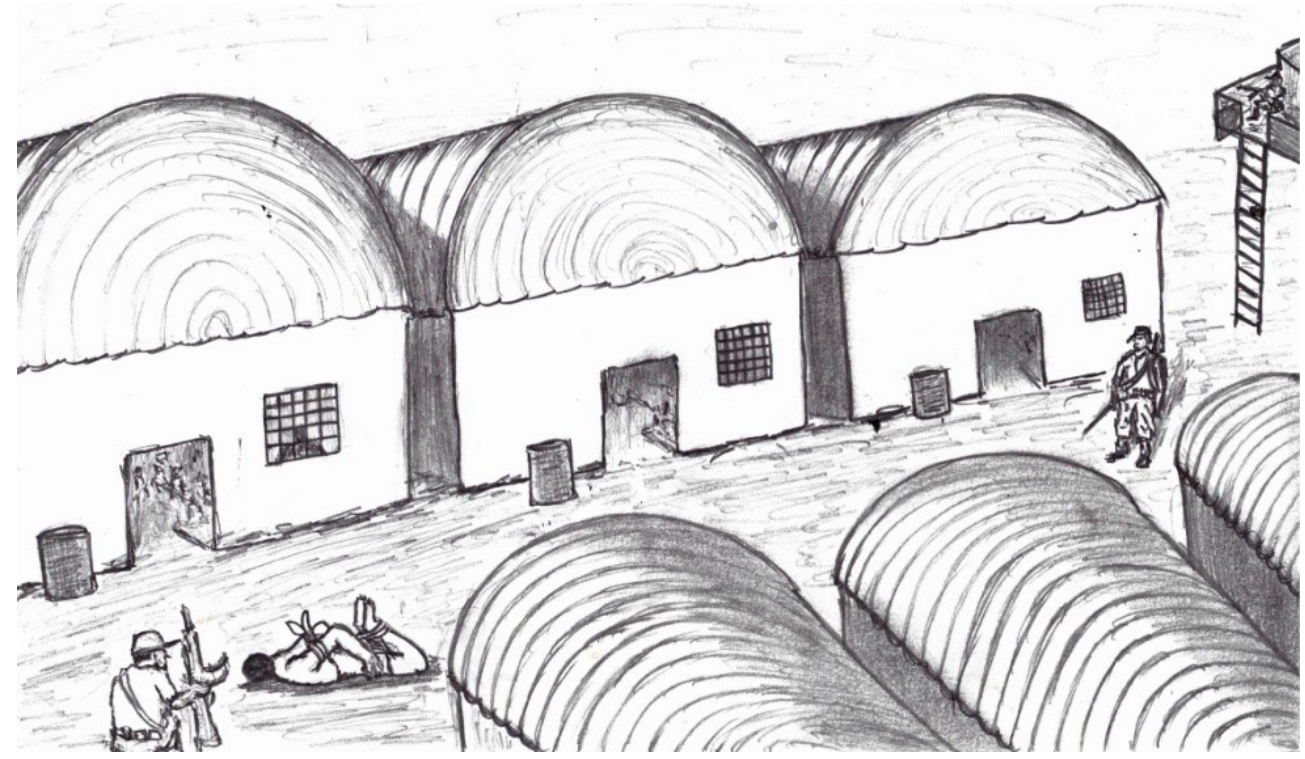

Figure 1: Drawing provided to the Office of the High Commissioner for Human Rights by an anonymous Eritrean torture survivor depicting "Otto," previously published with permission of the artist (Anonymous, United Nations, Human Rights Council, 2015, p286). 


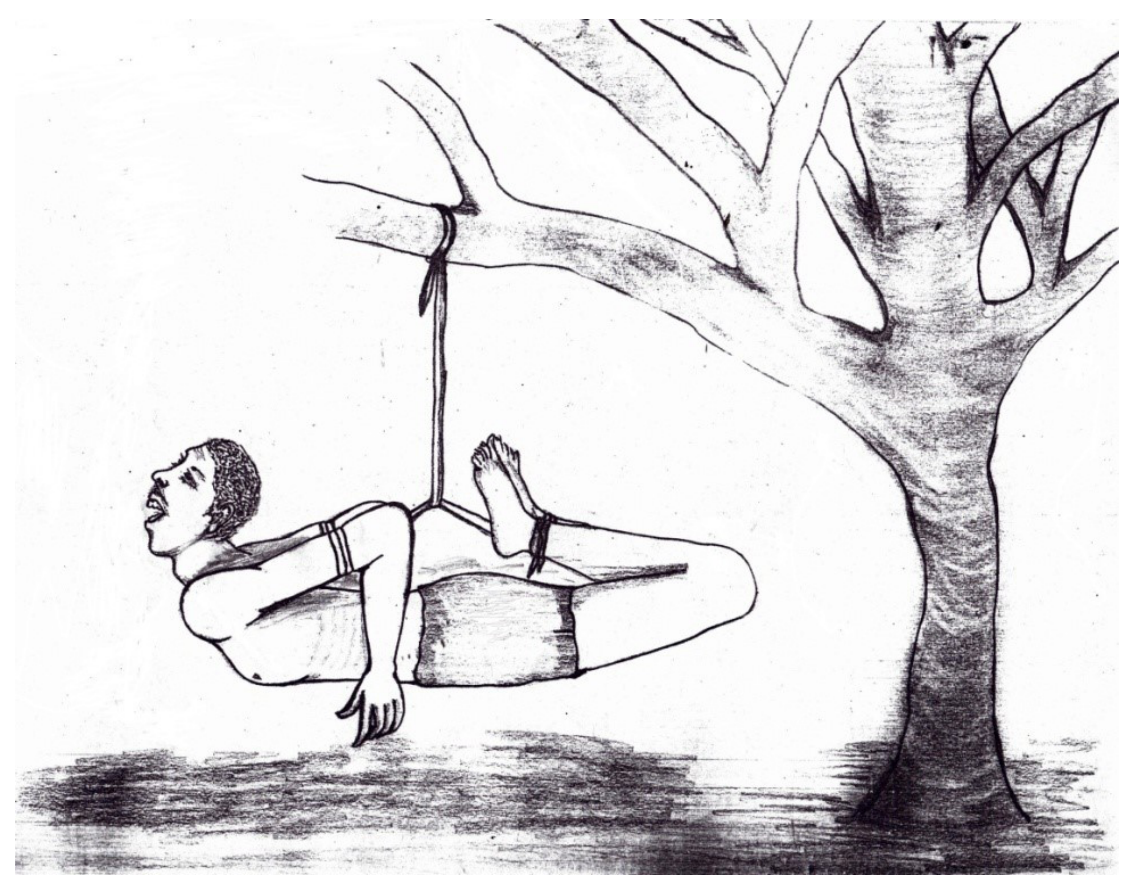

Figure 2: Drawing provided to the Office of the High Commissioner for Human Rights by an anonymous Eritrean torture survivor depicting "Helicopter," previously published with permission of the artist (United Nations, Human Rights Council, 2015, p286).

ordinarily weight-bearing joints. Findings were usually described by evaluators using the terms prescribed by the Istanbul Protocol (United Nations, Office of the High Commissioner for Human Rights, 1999), as summarized in Table 3.

No patterns of torture were identified which reliably differentiated detention centers within Eritrea, suggesting a relatively uniform culture of torture and abuse within the repressive elements of the Eritrean state (although our study was not designed statistically to evaluate this outcome and patterns might emerge from a larger dataset).
Table 3. Documented Physical and Psychological Sequelae of Torture

\begin{tabular}{lll}
\hline $\begin{array}{l}\text { Physical Findings } \\
\text { (Descriptors) }\end{array}$ & n & \% \\
\hline Typical & 1 & 1.7 \\
Highly Consistent & 43 & 72.9 \\
Consistent & 9 & 15.3 \\
Non-Istanbul Protocol De- & 6 & 10.2 \\
scriptors & & \\
\hline
\end{tabular}

Psychological Findings

$\begin{array}{lll}\text { DSM-V Criteria Met for } & 51 & 86.4\end{array}$ PTSD 


\section{Discussion}

Eritreans seeking asylum in Northern California corroborate previous reports of widespread human rights violations. Their accounts concur with those of thousands of other Eritrean asylum seekers interviewed in many different countries (United Nations, Human Rights Council, 2016). Civilians describe arbitrary arrest, enforced disappearance, imprisonment under inhumane conditions, and torture. Conscripts describe compulsory and indefinite military service in which the slightest resistance to authority is punished by indefinite detention, forced labor, interrogation, and torture. In both the civilian and military contexts, conditions of detention included overcrowding, light deprivation, lack of access to medical care, unsanitary conditions, and endemic diseases of squalor and overcrowding including diarrheal illness, skin infections, and arthropod infestations. In both contexts, the most prevalent forms of torture reported were beatings and other forms of blunt trauma, followed by positional torture such as "Otto" and "Helicopter". Head injuries were also commonly reported (40\%).

Our study had several limitations. We studied documents which were prepared for forensic rather than clinical or research purposes, and as such, they were structured to assist immigration officials in evaluating evidence rather than to conform to a prospective research protocol. For reasons stated above, FGC evaluations were excluded from this review, because they generally do not incorporate comprehensive trauma histories; however, because the prevalence of FGC in Eritrean women over 30 exceeds $90 \%$ (Zerai, 2003), the result was that almost no evaluations of Eritrean women were included. This study can therefore infer little about the experiences of forcibly displaced Eritrean women, although their experiences have elsewhere been described in detail (Gebreyesus et al., 2018; Gebreyesus et al., 2019; Lijnders, 2012). Additionally, because of cultural and religious factors, the incidence of sexual violence and rape reported for male asylum seekers is likely to be an underestimate.

Other geographic and socioeconomic biases exist in the data that could not have been avoided, even if the reports had been prepared with the present study in mind. All of the patients included in the study successfully escaped from Eritrea, survived their migration, and came to Northern California, a fact which implies a high average level of physical fitness, psychological resilience, and financial resources. It is possible that this subset of forcibly displaced Eritreans had systematically different experiences within Eritrea than other groups of compatriots, such as those who fled into neighboring countries and resettled there, attempted the Mediterranean crossing, or took the dangerous overland route through the Sinai to Israel, although larger studies than the present one suggest a chilling homogeneity of inhumanity (United Nations, Human Rights Council, 2016).

Nevertheless, some conclusions are possible. First, male Eritrean asylum seekers are very likely to have been imprisoned and tortured. Second, such torture, when experienced, is likely to have involved blunt trauma and forced positioning. Therefore, clinicians who serve communities in the Eritrean diaspora, or find themselves caring for an Eritrean immigrant for the first time, should be alert to the probability of PTSD and other trauma-related disorders of mood and cognition, and should look specifically for physical sequelae of commonly described forms of torture, including traumatic brain injury and associated disorders such as post-traumatic headache, temporomandibular dysfunction, and neurocognitive impairment; musculoskeletal in- 
juries; and compressive neuropathies due to beating and forced positioning.

This study also illustrates the necessity for iterative epidemiological work in an era of increasing mobility and displacement to support clinicians' understanding of the background and shared experience of shifting diaspora communities.

Finally, the high prevalence of significant physical and psychological findings observed in the reports examined underscores the essential role of healthcare providers in documenting evidence of torture on behalf of asylum seekers, in order to assist immigration officials in deciding when to grant the protection of asylum (Dyer, 2019; McKenzie, Bauer \& Reynolds, 2019). Clinicians probing Eritrean patients about possible torture or abuse should be aware that persecution is often linked to the patient's tribal, religious or political identity (Abu Suhaiban, Grasser, \& Javanbakht, 2019).

\section{Conclusion}

This study adds epidemiological data to an existing international literature documenting a high prevalence of reported history of torture, and of physical and psychological manifestations which substantiate such reports, in Eritrean asylum seekers (Amnesty International, 2013; UNHCR, 1999; United Nations, Human Rights Council, 2016; United Nations, Human Rights Council, 2015). These findings should be situated within a broader understanding of the prevalence of torture and other traumatic experiences among forcibly displaced people who may seek help from primary care clinicians. Given the prevalence of torture and other forms of ill-treatment and their psychosomatic residua demonstrated in this and other studies of diaspora communities, it seems reasonable to recommend that all actors involved in asylum determinations and those who reg- ularly care for displaced people be versed in the principles of trauma-informed care (Substance Abuse and Mental Health Services Administration, 2014). Clinicians must also endeavor to be responsive to distant events which create waves of displacement, and to become familiar with horrors that are difficult to comprehend in order to provide appropriate care to survivors.

\section{References}

Abu Suhaiban, H., Grasser, L. R., \& Javanbakht, A. (2019). Mental health of refugees and torture survivors: A critical review of prevalence, predictors, and integrated care. International Fournal Of Environmental Research And Public Health, 16 (13), 2309. http://dx.doi.org/10.3390/ ijerph16132309

Amnesty International. Map of Secret Prison Network in Eritrea Pinpoints "Infrastructure of Repression.” (8 May 2013) https://www. amnestyusa.org/press-releases/map-ofsecret-prison-network-in-eritrea-pinpointsinfrastructure-of-repression/ [Accessed 16 April 2019]

Bullard, K. M. et al. (2018). Prevalence of diagnosed diabetes in adults by diabetes type - United States, 2016. MMWR Morbidity Mortality Weekly Report, 67 (12), 359-361. http:///dx.doi. org/10.15585/mmwr.mm6712a2

Crosby, S. S., Norredam, M., Paasch-Orlow, M. K., Piwowarczyk, L., Heeren, T., \& Grodin, H. A. (2006). Prevalence of torture survivors among foreign-born patients presenting to an urban ambulatory care practice. Fournal of General Internal Medicine, 21 (7), 764-768. http://dx.doi. org/10.1111/j.1525-1497.2006.00488.x

Dyer, C. (2019). Doctors have authority to assess injuries from alleged torture, says Supreme Court. BMJ, 364, 11121. http://dx.doi.org/10. 1136/bmj.11121

Eisenman, D. P., Gelberg, L., Liu, H., \& Shapiro, M. F. (2003). Mental health and health related quality of life among adult Latino primary care patients living in the United States with previous exposure to political violence. $\mathcal{F} A M A$, 290 (5), 627-634. http://dx.doi.org/10.1001/ jama.290.5.627

Eisenman, D. P., Keller, A. S., \& Kim, G. (2000). Survivors of torture in a general medical setting: How often have patients been tortured, and how often is it missed? Western fournal of Medicine, 
172 (5), 301-304. http://dx.doi.org/10.1136/ ewjm.172.5.301

Freburger, J. K., Holmes, G. M., Agans, R. P., Jackman, A. M., Darter, J. D., Wallace, A. S., Castel, L. D., Kalsbeek, W. D., \& Carey, T. S. (2009). The rising prevalence of chronic low back pain. Archives of Internal Medicine, 169 (3), 251-258. http://dx.doi.org/10.1001/ archinternmed.2008.543

Gebreyesus, T., et al. (2019). Violence en route: Eritrean women asylum seekers experiences of sexual violence while migrating to Israel. Health Care for Women International, 40 (7-9), 721-743. http://dx.doi.org/10.1080/07399332.2019.1566 336

Gebreyesus, T., et al. (2018). Life on the margins: the experiences of sexual violence and exploitation among Eritrean asylum-seeking women in Israel. BMC Women's Health, 18 (1), 135. http://dx.doi. org/10.1186/s12905-018-0624-y

Getnet B, Medhin G, Alem A. Symptoms of posttraumatic stress disorder and depression among Eritrean refugees in Ethiopia: identifying direct, meditating and moderating predictors from path analysis. BMF Open, 9 (1), e021142.

Hepner, T.R.. (2009). Generation nationalism and generation asylum: Eritrean migrants, the global diaspora, and the transnational nation-state. Diaspora, 18 (1/2), 184-189.

Hirt, N, \& Mohammed, A.S. (2013). Dreams don't come true in Eritrea: Anomie and family disintegration due to the structural militarisation of society. Fournal of Modern African Studies, 51 (1), 139-168

Ignatieff, M., Keeley, J., Ribble, B., \& McCammon, K. (2016). The Refugee and Migration Crisis: Proposals for action, UN Summit 2016. Brookings Institution. https://www.brookings.edu

Jonzon R, Lindkvist P, \& Johansson E. (2015). A state of limbo - in transition between two contexts: Health assessments upon arrival in Sweden as perceived by former Eritrean asylum seekers. Scandinavian fournal of Public Health. 43 (5), 548-558.

Kalt A, Hossein M, Kiss L, Zimmerman C. (2013). Asylum seekers, violence and health: a systematic review of research in high-income host countries. American fournal of Public Health 103 (3), e30-e42. doi: 10.2105/AJPH.2012.301136

Kirbreab G. (2009). Forced labour in Eritrea. Fournal of Modern African Studies, 47 (1), 41-72

Kibreab G. (2014). The open-ended Eritrean national service: The driver of forced migration. European Asylum Support Office Practical Cooperation Meeting on Eritrea. Valleta, Malta. October 2014.
Krug, E. G. et al., eds. (2002). World report on violence and health. Geneva, World Health Organization.

Lijnders, L. (2012). Caught in the borderlands: Torture experienced, expressed, and remembered by Eritrean asylum seekers in Israel. Oxford Monitor of Forced Migration, 2, 64-76. https:// www.oxforcedmigration.com

Marshall, G. N., Schell, T. L., Elliot, M. N., Berthold, S. M., \& Chun, C. A. (2005). Mental health of Cambodian refugees 2 decades after resettlement in the United States. $\mathcal{F} A M A, 294$ (5), 571-579. http://dx.doi.org/10.1001/jama.294.5.571

McKenzie, K. C., Bauer, J., \& Reynolds, P. P. (2019). Asylum seekers in a time of record forced global displacement: The role of physicians. Fournal of General Internal Medicine, 34 (1), 137-143. http:// dx.doi.org/10.1007/s1 1606-018-4524-5

Melamed, S, Chernet, A, Labhardt, N, ProbstHensch, N. (2019). Social resilience and mental health among Eritrean asylum-seekers in Switzerland. Qualitative Health Research. 29 (2), 222-236.

Metalios, E. E., Asgary, R. G., Cooperman, N., et al. (2008). Teaching residents to work with torture survivors: experiences from the Bronx Human Rights Clinic. Fournal of General Internal Medicine, 23 (7), 1038-1042. http://dx.doi. org/10.1007/s11606-008-0592-2

Siman-Tov M., Wang A., Alkan M., Adini B. (2019). Impact of traumatic events incurred by asylum seekers on mental health and utilization of medical services. Scandinavian fournal of Trauma, Resuscitation, and Emergency Medicine. 27 (85).

Substance Abuse and Mental Health Services Administration. (2014) Trauma-Informed Care in Behavioral Health Services. Treatment Improvement Protocol (TIP) Series 57. HHS Publication No. (SMA) 13-4801.

United Nations High Commissioner for Refugees (UNHCR), Global Trends: Forced Displacement In 2018, 2019. https://www.unhcr.org/ globaltrends2018/. [Accessed 19 June 2019]

United Nations High Commissioner for Refugees (UNHCR), UNHCR Mid-Year Trends 2018, 2018. https://www.unhcr.org/5c52ea084.pdf. [Accessed 24 April 2019]

United Nations, General Assembly, Convention Against Torture and Other Cruel, Inhuman or Degrading Treatment or Punishment, (10 December 1984, United Nations)

United Nations, Human Rights Council. Detailed findings of the commission of inquiry on human rights in Eritrea. A/HRC/32/CRP.1 (8 June 2016) United Nations, Human Rights Council. Report of 
the commission of inquiry on human rights in Eritrea. A/HRC/29/CRP.1 (5 June 2015)

United Nations, Human Rights Council. Report of the commission of inquiry on human rights in Eritrea. A/HRC/32/47 (9 May 2016)

United Nations, Office of the High Commissioner for Human Rights. Manual on the Effective Investigation and Documentation of Torture and Other Cruel, Inhuman or Degrading Treatment or Punishment ("Istanbul Protocol”), HR/P/ PT/8/Rev.1 (9 August 1999)

U.S. Census Bureau. https://factfinder. census.gov/faces/tableservices/jsf/pages/ productview.xhtml?pid=ACS_11_5YR_ B05006\&prodType $=$ table, $[$ Accessed 23 April 2019]

Virchow, R. (1985). Report on the typhus epidemic in Upper Silesia. In Rather, L. J. (ed.), Collected Essays on Public Health and Epidemiology (pp. 204319). Boston, MA: Science History Publications.

Walliman C \& Balthasar A. (2019). Primary care networks and Eritrean immigrants' experiences with health care professionals in Switzerland: A qualitative approach. International fournal of Enviromental Research and Public Health. 16 (14), 2614.

Zerai, W. (2003). A Study on Female Genital Mutilation in Eritrea. Norwegian Church Aid Programmes in Eastern Africa. http://www.stopfgm. net/wp-content/uploads/vor2013/grundlagen/ worku_zerai_fgm_eritrea_2003.pdf 